\title{
Kinetic parameters and reactivity for the steam gasification of coal chars obtained under different pyrolysis temperatures and pressures
}

\author{
J. Fermoso, M.V. Gil, S. García, C. Pevida, J.J. Pis, F. Rubiera* \\ Instituto Nacional del Carbón, INCAR-CSIC, Apartado 73, 33080 Oviedo, Spain
}

\begin{abstract}
The effect of devolatilization conditions (pressure and temperature) on the steam gasification kinetics and reactivity of coal chars was investigated. For this purpose, five different rank coals were selected: a lignite (LT), two high-volatile bituminous coals (DT and SA), a low-volatile bituminous coal (DI) and a semi-anthracite (HV). The coal chars were obtained by devolatilization in a novel pressurized fixed-bed reactor at temperatures of 800,900 and $1000^{\circ} \mathrm{C}$ and pressures of $1,5,10$ and 20 atm. The reactivity of the chars was studied by isothermal thermogravimetric analysis in a kinetically controlled regime at different temperatures under a steam atmosphere. The reactive behaviour of the chars was evaluated by means of the random pore model (RPM), which satisfactorily described the steam gasification of the coal chars. The gasification apparent reaction rate increased as the devolatilization pressure increased, whereas this parameter decreased as the devolatilization temperature increased.
\end{abstract}

Keywords: Coal char; High devolatilization pressure; Steam gasification; Random pore model; Kinetic parameters

\footnotetext{
* Corresponding author. Tel.: +34 985118 975; Fax: +34 985297662

E-mail address: frubiera@ incar.csic.es (F. Rubiera)
} 


\section{Introduction}

Coal is the most abundant and geographically most widely distributed fossil fuel. The stability of its supply and its relatively low cost ensure its inclusion in the energy mix in the foreseeable future. ${ }^{1}$ However, the use of coal in power plants generates a high amount of $\mathrm{CO}_{2}$, which is the major contributor to global climate change. The development and deployment of clean coal technologies with higher efficiencies will therefore be essential in the future to minimize the environmental impact of coal usage. Several advanced technologies, such as the integrated gasification combined cycle (IGCC) and pressurised fluidised bed combustion (PFBC), have proven to be viable alternatives for ensuring the clean use of coal. High operating pressures are possible with these technologies, e.g. 10-15 atm for PFBC, and 15-25 atm for IGCC. These technologies offer several advantages over conventional coal-firing processes, such as an increase in coal throughput, a reduction in pollutant emissions and an enhancement of the reaction. ${ }^{2}$

The gasification process converts the fuel into a mixture of gases such as carbon monoxide, hydrogen and light hydrocarbons. This gas mixture is then suitable for direct use in combined-cycle gas turbine systems or can be used as syngas. The syngas has a high calorific value and can replace fossil fuels in high efficiency power generation, heat or combined heat and power applications and in the production of liquid fuels and chemicals via synthesis gas. ${ }^{3}$ Gasification is usually carried out with air, oxygen or steam mixtures. The advantage of using steam is that this process yields higher amounts of hydrogen. ${ }^{4}$

Devolatilization is the first step in the coal gasification process, and the experimental conditions are bound to have an effect on the volatiles released and on the remaining 
char. The evolution of the structural and chemical modifications of the char during the devolatilization process will also have an important influence on the subsequent gasification rate. ${ }^{5}$ In short, the devolatilization conditions will affect the reactivity of the resulting char and hence the overall performance of the coal gasifier. ${ }^{6}$ Knowledge about the reactivity of the char during the gasification process and about the kinetics of the gasification reaction is therefore essential for designing gasifiers. ${ }^{7}$

The effect of devolatilization pressure on char formation has attracted widespread attention in recent years because of the development and implementation of combined cycle processes and pressurized facilities, such as IGCC and PFBC, for coal use. ${ }^{2}$ Greater feedstock reactivity would contribute directly to improving the cycle efficiency, with an accompanying potential reduction in operating costs and environmental impact ${ }^{8}$. Some studies have been carried out to assess the effect of pyrolysis pressure on char structure and morphology ${ }^{9}$ and char air/ $\mathrm{CO}_{2}$ gasification reactivity. ${ }^{5,10,11}$ It has been found that chars with different structures may behave differently during subsequent combustion. ${ }^{12}$ However, the reactivity of chars obtained at high pressure under steam gasification has scarcely been studied. ${ }^{13}$

Thermogravimetric analysis (TGA) is a useful, simple and fast tool for investigating and comparing thermal behaviour, reactivity and kinetics parameters during the pyrolysis, combustion and gasification of carbonaceous materials. ${ }^{14-17}$ Different models from the bibliography have been used in order to predict the behaviour of coal during gasification and calculate the kinetic parameters of the gasification reaction. ${ }^{6,18,19}$ The random pore model (RPM) proposed by Bhatia and Perlmutter ${ }^{20}$ has been widely applied to the experimental data obtained from the gasification of carbonaceous materials. ${ }^{4,21-24}$ 
In a previous work, Fermoso et al. $^{25}$ studied the influence of the pressure and temperature of devolatilization on the morphology of coal chars, and the effect of char morphology on their gasification reactivity was also deduced. The present presents a kinetic analysis of the steam gasification of coal chars prepared under different pyrolysis conditions by using isothermal thermogravimetric analysis. The objectives of this work were to obtain the kinetic parameters for steam gasification using the random pore model, and to study the effect of the devolatilization conditions on the gasification kinetics and reactivity of chars prepared from different rank coals. The reaction order with respect to steam was also calculated.

\section{Experimental Section}

2.1. Coal samples. Five coals were selected for this study: a lignite (LT), two highvolatile bituminous coals (DT and SA), a low-volatile bituminous coal (DI) and a semianthracite (HV). The samples were ground and sieved to obtain a particle size fraction of $75-150 \mu \mathrm{m}$. The proximate and ultimate analyses of the samples are shown in Table 1.

2.2. Char preparation. The chars were produced by devolatilizing the raw coals in a novel pressurized fixed-bed reactor. Details of the experimental device are given elsewhere. ${ }^{26}$ Briefly, it consists of a stainless-steel SS310 tubular reactor (internal diameter, $13 \mathrm{~mm}$; height, $305 \mathrm{~mm}$ ) with a porous plate, which is able to work at a maximum pressure of 20 atm at $1000^{\circ} \mathrm{C}$. Coal particles are fed into the system from a pressurised hopper. The mass flow rate of the solids is controlled using a pneumatically actuated three-way valve, which discharges the sample into the reactor in a semi- 
continuous mode, so that the time interval between discharges can be adjusted. Thus, the calculated heating rate for the particles is approximately $5000{ }^{\circ} \mathrm{C} \mathrm{s}^{-1}$. The char particles are collected on the porous plate inside the reactor. A thermocouple is in contact with the sample bed. The pressure is measured by a pressure transducer and automatically controlled by a microvalve.

The pyrolysis process was carried out isothermally at temperatures of 800,900 and $1000{ }^{\circ} \mathrm{C}$ and at pressures of $1,5,10$ and 20 atm. A total gas flow rate of $300 \mathrm{NmL} \mathrm{min}^{-1}$ was used and 3 vol.\% oxygen was added to the nitrogen stream in order to burn the released volatiles and to prevent the formation of soot. The chars were denoted by coal acronyms followed by the pyrolysis conditions; e.g., SA1000-1 stands for the char obtained from coal SA at $1000{ }^{\circ} \mathrm{C}$ and 1 atm.

2.3. Steam gasification reactivity tests. The steam gasification reactivity tests of the coal chars produced by devolatilization in the pressurized fixed-bed reactor were conducted under isothermal conditions at atmospheric pressure in a thermobalance (Setaram TAG24). Approximately $5 \mathrm{mg}$ of char sample was placed in a crucible with a circular base (diameter, $5 \mathrm{~mm}$; height, $2 \mathrm{~mm}$ ). A thermocouple was located close to the platinum basket in order to monitor the temperature and to close the oven control loop. All the char samples were subjected to gasification tests under isothermal conditions at the following temperatures: $850,900,950,1000$ and $1050^{\circ} \mathrm{C}$. A nitrogen flow rate of $50 \mathrm{NmL} \mathrm{m^{-1 }}$ was used to sweep the reactor during $15 \mathrm{~min}$, after which the temperature was increased from room temperature to the required experimental temperature at a heating rate of $50{ }^{\circ} \mathrm{C} \mathrm{min}^{-1}$, this temperature being maintained for another $15 \mathrm{~min}$. Next, char gasification was initiated by switching to 30 vol. $\% \mathrm{H}_{2} \mathrm{O}(\mathrm{v})$ and 70 vol. $\% \mathrm{~N}_{2}$ at a 
total flow rate of $150 \mathrm{NmL} \mathrm{min}^{-1}$. The sample was then allowed to react until completion. The steam generator consisted of a controlled evaporator and mixer (CEM), in which water and $\mathrm{N}_{2}$ were mixed and heated to the desired temperature $\left(150{ }^{\circ} \mathrm{C}\right)$. Liquid and gas mass flow controllers were used to control the flow rates of the water and nitrogen in order to ensure that the steam concentration remained constant.

In order to calculate the reaction order with respect to the steam, additional gasification tests were carried out under different steam concentrations $(10-40$ vol. \%) at atmospheric pressure and a fixed temperature of $1000^{\circ} \mathrm{C}$ for each char.

2.4. Kinetic model. The char conversion, $X$, and reaction rate, $\mathrm{d} X / \mathrm{d} t$, were calculated from the results of the thermogravimetric analyses. The random pore model, RPM, ${ }^{20}$ was used in order to evaluate the reactive behaviour of the chars. The reaction rate, $\mathrm{d} X / \mathrm{d} t$, is expressed as:

$\mathrm{d} X / \mathrm{d} t=k(1-X)[1-\psi \ln (1-X)]^{1 / 2}$

where $X$ is the char conversion on a dry ash-free basis, $k$ is the gasification apparent reaction rate and $\psi$ is a parameter related to the pore structure of the unreacted sample $(X=0)$. The apparent reaction rate, $k$, can be expressed using the Arrhenius equation:

$k=k_{0} \mathrm{e}^{-E / R T}$

where $k_{0}$ and $E$ are the pre-exponential factor and the activation energy, respectively. The parameter $\psi$ can be calculated by the following equation:

$\psi=4 \pi L_{0}\left(1-\varepsilon_{0}\right) / S_{0}^{2}$

where $S_{0}, L_{0}$ and $\varepsilon_{0}$ represent the pore surface area, the pore length and the porosity of the solid, respectively. Eq. (1) was linearised in order to calculate the values of $k$ and $\psi$ from the experimental data obtained in the isothermal thermogravimetric runs, giving: 
$(2 / \psi)\left[(1-\psi \ln (1-X))^{1 / 2}-1\right]=k t$

The random pore model provides the following conversion-time relationship: ${ }^{27}$

$X=1-\exp [-k t(1+k t \psi / 4)]$

$X_{\text {calc, } i}$ was calculated by introducing the previously estimated $k$ (calculated from $k_{0}$ and $E$ by means of Eq. (2)) and $\psi$ values into Eq. (5). $X$ was calculated in order to assess the quality of the fit and the capacity of the kinetic models for describing the char conversion by comparing the experimental and calculated $X$ values. The deviation (DEV) between the experimental and calculated curves was obtained using the following expression:

$\operatorname{DEV~} X(\%)=100\left[\Sigma_{i=1, N}\left(X_{\mathrm{exp}, i}-X_{\mathrm{calc}, i}\right)^{2} / \mathrm{N}\right]^{1 / 2} / \max X_{\exp }$

where $X_{\exp , i}$ and $X_{\mathrm{calc}, i}$ represent the experimental and calculated data of $X$ respectively, $N$ is the number of data points, and $\max X_{\exp }$ is the highest absolute value of the experimental curve.

2.5. Reaction order of the chars with respect to steam. The dependence of the apparent reaction rate on the reaction order can be described by means of the following equation:

$k=b P_{\mathrm{H} 2 \mathrm{O}}^{n}$

where $k$ is the apparent reaction rate, $b$ is a constant, $P_{\mathrm{H} 2 \mathrm{O}}$ is the steam partial pressure and $n$ is the reaction order with respect to the steam. The apparent reaction rate, $k$, was calculated using the RPM. The reaction order with respect to the steam, $n$, was calculated from the slope of the log-log plot of the apparent reaction rate versus the steam partial pressure, $P_{\mathrm{H} 2 \mathrm{O}}$. 


\section{Results and Discussion}

3.1. Kinetic parameters. The linearised form of the RPM model, Eq. (4), was used to represent the experimental data obtained at all the temperatures studied in order to find the parameters $k$ and $\psi$ of best fit. As an example, the results for the DI and HV coal chars are shown in Fig. 1. The parameter $\psi$ was calculated assuming that its value is constant for each char sample at all the temperatures, since it is related to the initial pore structure. The Arrhenius plot (lnk vs. 1/T), represented in Fig. 2, was then employed to calculate the activation energy, $E$, and the pre-exponential factor, $k_{0}$, for each of the char samples (Eq. 2). All of the regression analyses yielded statistically significant results (95\% confidence interval). Table 2 shows the values of $E, k_{0}$ and $\psi$ that allow the best fit of the experimental data to the RPM model. The values of the activation energy varied between 183 and $206 \mathrm{~kJ} \mathrm{~mol}^{-1}$ and those of the pre-exponential factor between 1.63E+06 and 3.64E+07 $\mathrm{min}^{-1}$ for all of the coal chars studied. For the LT char, the $\psi$ value obtained was equal to zero. When this occurs, according to Eq. (1), the RPM model predicts a constant decrease in the gasification rate with conversion, resulting in the volumetric model (VM), which assumes a homogeneous reaction throughout the particle. $^{28}$

In order to assess the ability of the model to predict conversion during steam gasification, the experimental conversion values, $X_{\text {exp, }, i}$, were compared with the calculated values, $X_{\text {calc }, i}$, at the different temperatures selected. The calculated conversion value of the chars during gasification, $X_{\mathrm{calc}, i}$, was obtained by introducing the previously estimated $k$ (calculated from $k_{0}$ and $E$ ) and $\psi$ values into Eq. (5). The results obtained are shown in Fig. 3. In addition, the errors produced by the kinetic models in predicting the values of conversion were quantified by means of Eq. (6), which 
compares the experimental and calculated $X$ values by obtaining the deviation, DEV $X$ (\%), between the experimental and calculated curves. The DEV $X$ values were low for all the char samples studied, ranging from 0.6 to $5.6 \%$. This shows that the RPM model (or the VM model in the case of char LT) gives a good prediction of conversion for the coal chars studied.

\subsection{Effect of the devolatilization conditions on char gasification kinetics and reactivity.}

\subsubsection{Effect of the devolatilization pressure}

Previous works have shown that pressure plays a key role in the formation of char during pyrolysis in pressurized reaction systems. ${ }^{25,29,30}$ Furthermore, it seems that the pressure at which the parent coal is devolatilized may have an important influence on the reactivity of the resulting char. In this work, the effect of the devolatilization pressure was studied using the high-volatile bituminous coal SA, which was devolatilizated at $1000^{\circ} \mathrm{C}$ at pressures of $1,5,10$ and 20 atm. Likewise, the other coals (LT, DT, DI and HV) were devolatilizated at $1000{ }^{\circ} \mathrm{C}$ at pressures of 1 and 20 atm.

Monson et al. ${ }^{31}$ concluded that the combustion kinetic parameters obtained under lowpressure conditions cannot be accurately extrapolated to elevated pressures. Matsumoto et al. ${ }^{22}$ suggested that the value of $E$ may be affected by the different conditions governing the formation of the char. In the present study, both the $E$ and $k_{0}$ values increased slightly as the devolatilization pressure increased (Table 2), although no differences were observed in the case of the LT coal char. No clear tendency for the $E$ and $k_{0}$ values in relation to devolatilization temperature was observed (Table 2). 
The RPM model gave a different value of $\psi$ for the chars obtained at 1 and 20 atm in the case of the DT, SA and DI coals, which could be indicative of the effect of the devolatilization pressure on the porous structure of the char derived from bituminous coals. In a previous work, Fermoso et al. ${ }^{25}$ reported that pyrolysis pressure had a significant impact on the porous structure in bituminous coals. However for coals LT and $\mathrm{HV}$ the $\psi$ values at 1 and 20 atm were similar. The $\psi$ value of the chars obtained from coal SA at different devolatilization temperatures varied, showing the influence of temperature during the pyrolysis process on the pore structure of the char. In general, the $\psi$ value decreased as the pyrolysis pressure increased, whereas it increased with the devolatilization temperature. As $\psi$ increases, the maximum reaction rate shifts to higher conversion values, ${ }^{32}$ which suggests a higher char reactivity as the devolatilization pressure increases, but a lower char reactivity as the pyrolysis temperature increases.

Fig. 4 shows the gasification apparent reaction rate, $k$, for some coal chars at different gasification temperatures as a function of the devolatilization pressure (Fig. 4a) and temperature (Fig. 4b). No differences in the $k$ values were observed for the LT coal chars at different devolatilization pressures (data not shown), probably because LT is a low rank coal with a high reactivity and its behaviour would therefore be less sensitive to pressure. Very few changes occurred in the external morphology of the lignite char particles at 1 and 20 atm since they had a similar external angular shape, as it was observed in previous studies ${ }^{25}$, which could explain why no differences in their steam gasification reactivity were observed.

For the other coal chars, it can be seen that the apparent reaction rate increased with the devolatilization pressure (Fig. 4a). The apparent reaction rate also increased with the gasification temperature. This is because at higher gasification temperatures, the 
reaction is able to acquire more energy which in turn accelerates the reaction under chemical control. ${ }^{6}$

Several authors, however, have observed a decrease in coal char reactivity as the pyrolysis pressure increases. Gadiou et al. ${ }^{5}$ observed that an increase in pyrolysis pressure augmented the carbon content of the char, whereas its oxygen and hydrogen contents decreased. These authors pointed out that, due to the increase in the devolatilization of hydrogen from the char with the rise in pyrolysis pressure, a decrease in char reactivity can be expected as the pressure of devolatilization increases. Furthermore, they also found that a rise in pyrolysis pressure led to a greater graphitization of the carbonaceous solid.

Sha et al. ${ }^{33}$ found that the reactivity of coal chars under a hydrogen atmosphere decreased as the pyrolysis pressure increased, supposedly due to the effect of pressure on the pore structure. Lee et al. ${ }^{34}$ showed that the greater fluidity that resulted from high-pressure pyrolysis led to an enhanced ordering of the carbon layers and the subsequent loss of gasification reactivity in the char residue. It seems therefore that the pore area available for reaction decreases with the rise in devolatilization pressure.

In the present study, this effect was not observed, since the char gasification reactivity increased with the pyrolysis pressure. The variation in the $k$ value with pyrolysis pressure was lower in the HV coal than in the other coals (Fig. 4a). The bulk density of the chars derived from the semi-anthracite, HV, hardly changed at all with pyrolysis pressure $^{25}$. In contrast, the chars from the bituminous coals (DI, DT and SA) had bulk density values significantly smaller after pyrolysis at $20 \mathrm{~atm}$ due to the greater degree of swelling observed in the bituminous coals obtained at high pressure ${ }^{25}$. An increase in devolatilization pressure must therefore have led to greater swelling and produced larger 
particles with thinner pore walls. In fact, at atmospheric pressure vitrinite-derived chars from bituminous coals displayed thick walls with a central pore surrounded by a thick and porous outer shell, whereas when the pyrolysis pressure was increased, these particles swelled, giving rise to larger central voids and thinner walls, and in some cases, e.g. SA1000-10 and SA1000-20, the fragmentation of the swollen very thinwalled particles. $^{25}$

Gadiou et al. ${ }^{5}$ also observed an increase in the swelling of the coal char with increasing pyrolysis pressure. According to Lee et al., ${ }^{35}$ a coal with almost no signs of swelling at atmospheric pressure can swell significantly under elevated pressures. An initial increase in external pressure reduces the total volatile yield and enhances secondary tar reactions, which results in more low-molecular-weight volatiles being retained in the char residue. A high external pressure may also increase the resistance to the expansion inside the particle. However, as more low-molecular-weight volatiles are retained inside the residue at high pressure, the fluidity of the residue is enhanced, since the volatiles act as a plasticizing agent enhancing the fluidity of the plastic mass. Consequently, swelling increases as the pressure reaches a certain level, due to a decrease in the resistance of the shell which is a result of the increased fluidity of the residue.

Benfell et al. ${ }^{10}$ found that pyrolysis pressure affected primarily the structure, and in particular the surface area, of the char; an increase in the surface area means that the micropores are more accessible to the gasifying medium. Thus, highly porous chars produced at high pressure burn more rapidly than less porous chars produced at low pressure, due to their thinner walls, higher internal and external surface areas and higher fragmentation during combustion. ${ }^{10}$ Lee et al. ${ }^{35}$ also observed that chars generated at 
high pressure had a greater number of larger holes and more spherical and thin-walled particles (cenospheres) than those generated at low pressure.

The internal surface area of a char is one of the parameters used to interpret a char reaction rate, particularly under gasification conditions. ${ }^{2}$ Although the relationship between surface area and reaction rate has been widely investigated, there is still no general agreement. An increase in the surface area seems to result in an increase in the gasification reaction rate, but only up to a maximum value and then decreases, while the surface area continues to increase. ${ }^{6}$ According to most studies, the reaction rate decreases due to the reduction in the number of active sites. The micropore surface area of the chars studied in the present paper showed a linear increase with the pyrolysis pressure. $^{25}$

Furthermore, in the present work, the heating rate during the devolatilization process was very high (approximately $5000{ }^{\circ} \mathrm{C} \mathrm{s}^{-1}$ ). Higher heating rates during the devolatilization stage cause the fragmentation of char particles due to the violent release of volatile matter, leading to fractured char particles and so a higher concentration of active sites. ${ }^{36}$ Thus, the rapid devolatilization of the coal in rapid pyrolysis favours the formation of char with a high porosity and reactivity. ${ }^{37}$ The fragmentation phenomenon was observed in the case of the high-volatile bituminous coal SA, as it was mentioned above.

\subsubsection{Effect of the devolatilization temperature}

Temperature may also have a considerable influence on the resulting char structure and

reactivity. ${ }^{32,38}$ In the present work, the effect of the devolatilization temperature was 
studied using the high-volatile bituminous coal SA, which was devolatilizated at 20 atm at temperatures of 800,900 and $1000{ }^{\circ} \mathrm{C}$.

Fig. $4 \mathrm{~b}$ shows that the apparent reaction rate of the chars decreased with the rise in devolatilization temperature. However, in all cases, the apparent reaction rate increased with the gasification temperature.

Maloney and Jenkins ${ }^{39}$ found that the air reactivity of chars produced by the rapid pyrolysis of low- and high-volatile bituminous coals decreased with the rise in pyrolysis temperature from 800 to $1000{ }^{\circ} \mathrm{C}$. Wu el al. ${ }^{6}$ also found that the steam gasification reaction rate decreased with the increase in pyrolysis temperature. Cai et al. ${ }^{11}$ observed marked reductions in the combustion reactivity of the coal chars as the pyrolysis temperature rose from 700 to $1500{ }^{\circ} \mathrm{C}$. According to these authors, the decrease in char hydrogen content observed with increasing temperature is probably associated with the decrease in char reactivity. During the pyrolysis process, the release of aliphatic carbon from bituminous coals and lignite leads to a greater carbon aromaticity in the remaining char, which is accompanied by the release of aliphatic hydrogen and oxygen. Although only part of the carbon active sites is associated with bonded hydrogen, the loss of hydrogen leads to a decrease in the reactivity of the resultant char to a certain extent. ${ }^{40}$ The hydrogen content of the chars studied in the present work decreased with the rise in devolatilization temperature, as it was shown by Fermoso et al. ${ }^{25}$. Maloney and Jenkins ${ }^{39}$ suggested that the $\mathrm{H}$ content of char is related to structural disorder and is, therefore, an indication of the concentration of active sites.

On the other hand, decreasing reactivity with the rise in devolatilization temperature has been attributed to progressive thermal annealing of the chars, ${ }^{41}$ resulting in more ordered carbon structures, i. e., a smaller number of active surface areas. This causes the 
deactivation of the char due to the realignment of the coal layer planes, resulting in a smaller amount of micropore surface area being accessible to the reactant gas. ${ }^{40}$

\subsection{Effect of the steam concentration on char reactivity.}

The increase in steam partial pressure during the isothermal gasification at atmospheric pressure led to an increase in the reactivity of all the studied chars, independently of the devolatilization conditions (pressure and temperature) and the rank of the coal from which they were obtained. The reaction order with respect to the steam, $n$, for each char was calculated according to Eq. (7). Fig. 5 shows the log-log plot of the apparent reaction rate for some of the char samples with respect to the steam partial pressure, which was employed to calculate the reaction orders. The experimental results obtained are shown in Table 2, and they were between $0.52-0.60$ and $0.42-0.61$ for coal chars obtained at 1 and 20 atm, respectively. In the case of the chars obtained from coal SA at 20 atm and different temperatures, $800-1000^{\circ} \mathrm{C}$, the reaction orders were between 0.49 0.64. The values obtained in this work are in agreement with those of other authors. ${ }^{4,42,43}$ However, from our experiments no relevant effect of the devolatilization conditions (pressure and temperature) on the reaction order with respect to the steam was observed.

\section{Conclusions}

The reactive behaviour of the bituminous and semianthracite coal chars was satisfactorily predicted using the random pore model (RPM), whereas that of the lignite coal chars was better described by the volumetric model (VM), which is a simplified form of the first model. The chars obtained at elevated pressure were found to be more 
reactive than those produced at atmospheric pressure, probably because they experienced a higher degree of swelling and had a higher bulk density and porosity. However, an increase in the devolatilization temperature led to a decrease in char reactivity, due to the thermal annealing of the chars and the subsequent decrease in the active surface area. It was also found that the higher the gasification temperature, the higher the char reactivity.

\section{Acknowledgements}

M.V. Gil acknowledges funding from the CSIC JAE Program co-financed by the European Social Fund.

\section{References}

(1) Buhre, B. J. P.; Elliott, L. K.; Sheng, C. D.; Gupta, R. P.; Wall, T. F. Prog. Energy Combust. Sci. 2005, 31, 283-307.

(2) Wall, T. F.; Liu, G.-S.; Wu, H.-W.; Roberts, D. G.; Benfell, K. E.; Gupta, S.; Lucas, J. A.; Harris D. J. Prog. Energy Combust. Sci. 2002, 28, 405-453.

(3) Yassin, L.; Lettieri, P.; Simons, S. J. R.; Germanà, A. Chem. Eng. J. 2009, 146, 315327.

(4) Fermoso, J.; Arias, B.; Pevida, C., Plaza, M. G.; Rubiera, F.; Pis, J. J. J. Therm. Anal. Calorim. 2008, 91, 779-786.

(5) Gadiou, T.; Bouzidi, Y.; Prado, G. 2002. Fuel 2002, 81, 2121-2130.

(6) Wu, S.; Gu, J.; Li, L.; Wu, Y.; Gao, J. Process Saf. Environ. Protect. 2006, 84, 420428.

(7) Liu, G.-S.; Tate, A. G.; Bryant, G. W.; Wall, T. F. Fuel 2000, 79, 1145-1154.

(8) Megaritis, A.; Messenböck, R. C.; Chatzakis, I. N.; Dugwell, D. R.; Kandiyoti, R. Fuel 1999, 78, 871-882.

(9) Yu, J.; Harris, D.; Lucas, J.; Roberts, D.; Wu, H.; Wall, T. Energy Fuels 2004, 18, 1346-1353.

(10) Benfell, K. E.; Liu, G.-S.; Roberts, D. G.; Harris, D. J.; Lucas, J. A.; Bailey, J. G.; Wall, T. F. Proc. Combust. Inst. 2000, 28, 2233-2241.

(11) Cai, H.-Y.; Güell, A. J.; Chatzakis, I. N.; Lim, J.-Y.; Dugwell, D. R.; Kandiyoti, R. Fuel 1996, 75, 15-24.

(12) Liu, G.-S.; Rezaeia, H. R.; Lucasa, J. A.; Harris, D. J.; Wall, T. F. Fuel 2000, 79, 1767-1779.

(13) Chitsora, C. T.; Mühlen, H.-J.; van Heek, K. H.; Jüntgen, H. Fuel Process. Technol. 1987, 15, 17-29. 
(14) Arenillas, A.; Rubiera, F.; Pis, J. J.; Jones, J. M.; Williams, A. Fuel 1999, 78, 1779-1785.

(15) Arenillas, A.; Rubiera, F.; Pis, J. J.; Cuesta, M. J.; Iglesias, M. J.; Jiménez, A.; Suárez-Ruiz, I. J. Anal. Appl. Pyrolysis 2003, 68-69, 371-385.

(16) Pis, J. J.; de la Puente, G.; Fuente, E.; Morán, A.; Rubiera, F. Thermochim. Acta 1996, 279, 93-101.

(17) Rubiera, F.; Arenillas, A.; Fuente, E.; Miles, N.; Pis, J. J. Powder Technol. 1999, 105, 351-356.

(18) Everson, R. C.; Neomagus, H. W. J. P.; Kaitano, R.; Falcon, R.; du Cann, V. M. Fuel 2008, 87, 3403-3408.

(19) Liu, H.; Luo, C.; Kato, S.; Uemiya, S.; Kaneko, M.; Kojima, T. Fuel Process. Technol. 2006, 87, 775-781.

(20) Bhatia, S. K.; Perlmutter, D. D. AIChE J. 1980, 26, 379-386.

(21) Kajitani, S.; Hara, S.; Matsuda, H. Fuel 2002, 81, 539-546.

(22) Matsumoto, K.; Takeno, K.; Ichinose, T.; Ogi, T.; Nakanishi, M. Fuel 2009, 88, 519-527.

(23) Okumura, Y.; Hanaoka, T.; Sakanishi, K. Proc. Combust. Inst. 2009, 32, 20132020.

(24) Zou, J.H.; Zhou, Z. J.; Wang, F. C.; Zhang, W.; Dai, Z. H.; Liu, H. F.; Yu, Z. H. Chem. Eng. Process. 2007, 46, 630-636.

(25) Fermoso, J.; Gil, M. V.; Borrego, A. G.; Pevida, C.; Pis, J. J.; Rubiera, F. Energy Fuels 2010, 24, 5586-5595.

(26) Fermoso, J.; Arias, B.; Plaza, M. G.; Pevida, C.; Rubiera, F.; Pis, J. J.; García-Peña, F.; Casero, P. Fuel Process. Technol. 2009, 90, 926-932.

(27) Tran, K. N.; Bathia, S. K.; Tomsett, A. Ind. Eng. Chem. Res. 2007, 46, 3265-3274.

(28) Ishida, M.; Wen, C. Y. Chem. Eng. Sci. 1971, 26 1031-1041.

(29) Wu, H.; Bryant, G. W.; Benfell, K. E.; Wall, T. F. Energy Fuels 2000, 14, 282-290.

(30) Yu, J.; Lucas, J. A.; Wall, T. F. Prog. Energy Combust. 2007, 33, 135-170.

(31) Monson, C. R.; Germane, G. J.; Blackham, A. J.; Smoot, L. D. Combust Flame 1995, 100, 669-683.

(32) Fermoso, J.; Stevanov, C.; Moghtaderi, B.; Arias, B.; Pevida, C.; Plaza, M. G.; Rubiera, F.; Pis, J. J. Anal. Appl. Pyrolysis 2009, 85, 287-293.

(33) Sha, X.-Z.; Chen, Y.-G.; Cao, J.; Yang, Y.-M.; Ra, D.-Q. Fuel 1990, 69, 656-659.

(34) Lee, C. W.; Jenkins, R. G.; Schobert, H. H. Energy Fuels 1992, 6, 40-47.

(35) Lee, C. W.; Scaroni, A. W.; Jenkins, R. G. Fuel 1991, 70, 957-965.

(36) Ashu, J. T.; Nsakala, M. Ya.; Mahajan, Om. P.; Walker Jr., P. L. Fuel 1978, 57, 250-251.

(37) Zanzi, R.; Sjoestroem, K.; Bjoernbom, E. Fuel 1996, 75, 454-550.

(38) van Heek, K. H.; Mühlen, H.-J. Fuel Process. Technol. 1987, 15, 113-133.

(39) Maloney, D. J.; Jenkins, R. G. Fuel 1985, 64, 1415-1422.

(40) Zhang, S.-Y.; Lu, J.-F.; Zhang, J.-S.; Yue, G.-X. Energy Fuels 2008, 22, 32133221 .

(41) Senneca, O.; Russo, P.; Salatino, P.; Masi, S. Carbon 1997, 35, 141-151.

(42) Linares-Solano, A.; Mahajan, O. P.; Walker, P. L. Fuel 1979, 58, 327-332.

(43) Zhang, L.; Huang, J.; Fang, Y.; Wang, Y. Energy Fuels 2006, 20, 1201-1210. 


\section{Figure captions}

Fig. 1. Plots of the RPM linearised model for the DI1000-1 (a), DI1000-20 (b), HV1000-1 (c) and HV1000-20 (d) chars during steam gasification $\left(30 \% \mathrm{H}_{2} \mathrm{O}(\mathrm{v})\right)$ at different temperatures.

Fig. 2. Arrhenius plot for the RPM model during steam gasification $\left(30 \% \mathrm{H}_{2} \mathrm{O}(\mathrm{v})\right)$ of the coal char samples obtained at $1000^{\circ} \mathrm{C}$ and 20 atm.

Fig. 3. Experimental conversion curves of DI and HV coal chars and those calculated with the RPM model during steam gasification $\left(30 \% \mathrm{H}_{2} \mathrm{O}(\mathrm{v})\right)$ at different temperatures.

Fig. 4. Effect of the devolatilization pressure (a) and temperature (b) on the gasification apparent reaction rate of char, $k$, for different gasification temperatures $(900,950,1000$ and $\left.1050{ }^{\circ} \mathrm{C}\right)$.

Fig. 5. Reactivity of coal chars obtained at $1000{ }^{\circ} \mathrm{C}$ and 20 atm as a function of the steam partial pressure. 
Table 1. Proximate and ultimate analyses of the coals

\begin{tabular}{|c|c|c|c|c|c|}
\hline Coal & LT & DT & SA & DI & $\mathrm{HV}$ \\
\hline Origin & Spain & China & $\begin{array}{l}\text { South } \\
\text { Africa }\end{array}$ & Spain & Spain \\
\hline Rank & lig & hvb & hvb & lvb & $\mathrm{sa}$ \\
\hline \multicolumn{6}{|l|}{ Proximate Analysis $^{\mathrm{a}}$} \\
\hline Moisture content (wt.\%) & 3.5 & 1.2 & 2.0 & 1.2 & 1.1 \\
\hline Ash (wt.\%, db) & 18.2 & 11.7 & 15.4 & 4.3 & 8.7 \\
\hline Volatile matter (wt.\%, db) & 38.9 & 28.5 & 26.7 & 16.1 & 10.5 \\
\hline Fixed carbon $(\text { wt. } \%, \mathrm{db})^{\mathrm{b}}$ & 42.9 & 59.8 & 57.9 & 79.6 & 80.8 \\
\hline \multicolumn{6}{|c|}{ Ultimate Analysis (wt.\%, daf) $^{\mathrm{a}}$} \\
\hline $\mathrm{C}$ & 57.5 & 81.2 & 81.4 & 86.4 & 87.7 \\
\hline $\mathrm{H}$ & 4.9 & 5.1 & 5.0 & 4.3 & 3.7 \\
\hline $\mathrm{N}$ & 0.5 & 1.1 & 2.4 & 1.9 & 2.8 \\
\hline S & 5.3 & 0.8 & 0.6 & 1.8 & 1.0 \\
\hline $\mathrm{O}^{\mathrm{b}}$ & 31.8 & 11.8 & 10.6 & 5.6 & 4.8 \\
\hline
\end{tabular}

lig: lignite; hvb: high-volatile bituminous coal; lvb: low-volatile bituminous coal; sa: semi-anthracite; db: dry basis; daf: dry and ash-free basis.

a The proximate analysis was conducted in a LECO TGA-601, and the ultimate analysis in a LECO CHNS-932.

${ }^{\mathrm{b}}$ Calculated by difference. 
Table 2

Values of activation energy, $E$, pre-exponential factor, $k_{0}$, and $\psi$ parameter during steam gasification $\left(30 \% \mathrm{H}_{2} \mathrm{O}(\mathrm{v})\right)$, together with reaction order with respect to steam, $n$, after gasification at $1000{ }^{\circ} \mathrm{C}$ and different steam concentrations $\left(10-40 \% \mathrm{H}_{2} \mathrm{O}(\mathrm{v})\right)$, obtained using the random pore model (RPM)

\begin{tabular}{lllll}
\hline Char sample & $E\left(\mathrm{~kJ} \mathrm{~mol}^{-1}\right)$ & $k_{0}\left(\mathrm{~min}^{-1}\right)$ & $\psi$ & $n$ \\
\hline LT1000-1 & 190 & $3.61 \mathrm{E}+07$ & 0 & 0.54 \\
LT1000-20 & 190 & $3.64 \mathrm{E}+07$ & 0 & 0.42 \\
\hline DT1000-1 & 196 & $9.12 \mathrm{E}+06$ & 3.68 & 0.59 \\
DT1000-20 & 206 & $2.92 \mathrm{E}+07$ & 2.35 & 0.47 \\
\hline SA1000-1 & 190 & $4.37 \mathrm{E}+06$ & 5.49 & 0.60 \\
SA1000-5 & 198 & $8.81 \mathrm{E}+06$ & 6.12 & 0.59 \\
SA1000-10 & 206 & $2.59 \mathrm{E}+07$ & 2.82 & 0.63 \\
SA1000-20 & 200 & $1.75 \mathrm{E}+07$ & 2.15 & 0.53 \\
SA900-20 & 186 & $5.01 \mathrm{E}+06$ & 1.88 & 0.49 \\
SA800-20 & 190 & $8.74 \mathrm{E}+06$ & 1.15 & 0.64 \\
\hline DI1000-1 & 178 & $1.63 \mathrm{E}+06$ & 3.28 & 0.52 \\
DI1000-20 & 200 & $1.60 \mathrm{E}+07$ & 4.35 & 0.50 \\
\hline HV1000-1 & 183 & $2.47 \mathrm{E}+06$ & 3.44 & 0.58 \\
HV1000-20 & 195 & $7.84 \mathrm{E}+06$ & 3.30 & 0.61 \\
\hline
\end{tabular}



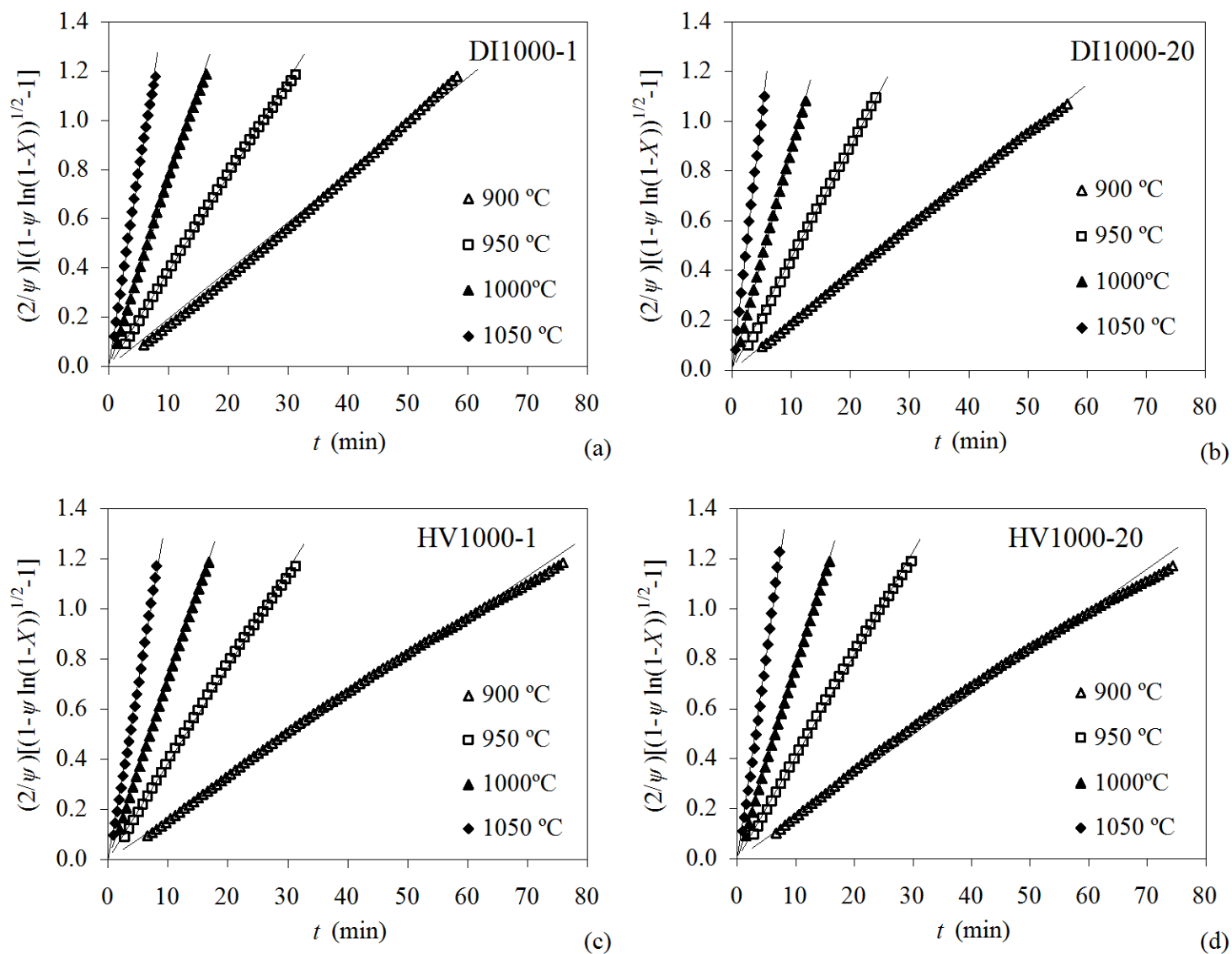

Fig. 1. Plots of the RPM linearised model for the DI1000-1 (a), DI1000-20 (b), HV1000-1 (c) and HV1000-20 (d) chars during steam gasification $\left(30 \% \mathrm{H}_{2} \mathrm{O}(\mathrm{v})\right)$ at different temperatures. 


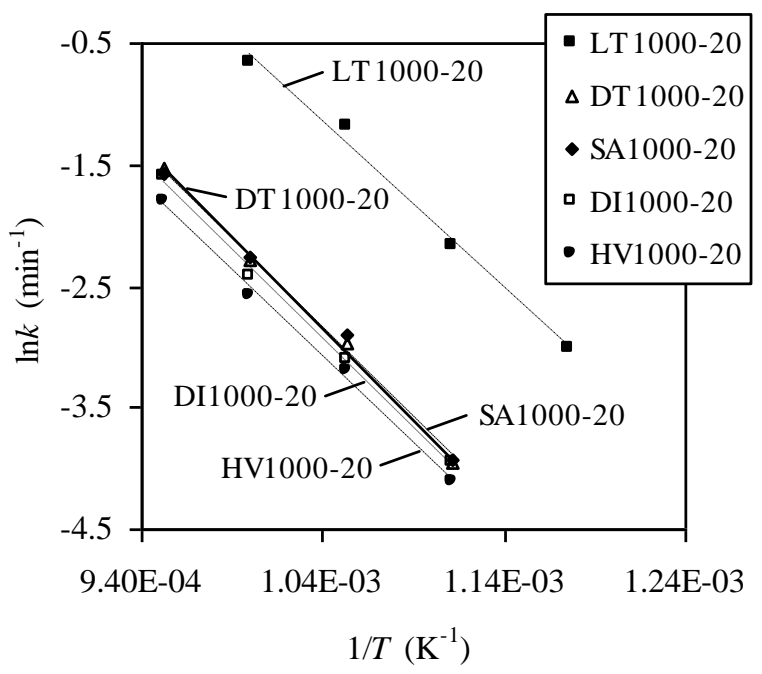

Fig. 2. Arrhenius plot for the RPM model during steam gasification $\left(30 \% \mathrm{H}_{2} \mathrm{O}(\mathrm{v})\right)$ of the coal char samples obtained at $1000{ }^{\circ} \mathrm{C}$ and 20 atm. 

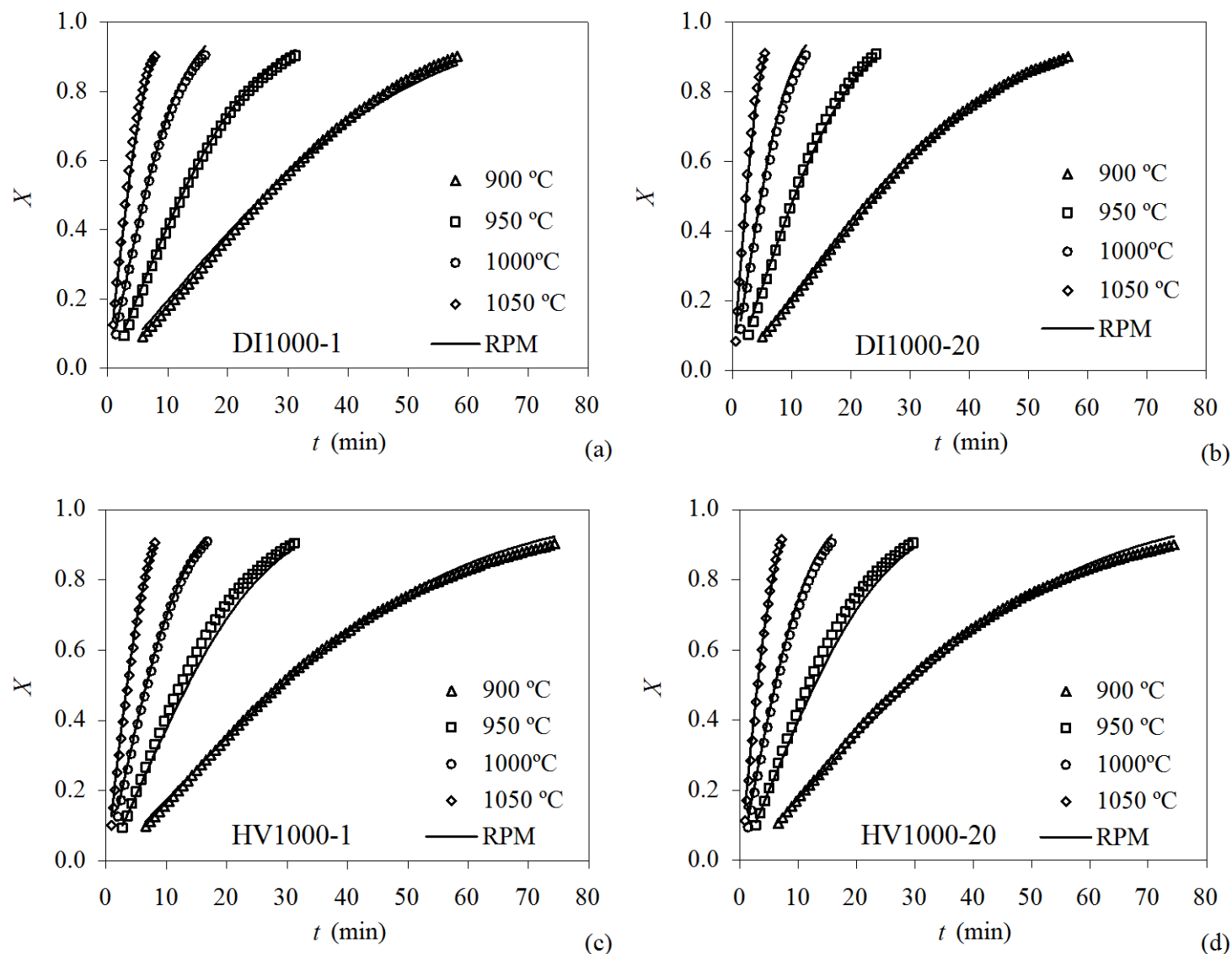

Fig. 3. Experimental conversion curves of DI and HV coal chars and those calculated with the RPM model during steam gasification $\left(30 \% \mathrm{H}_{2} \mathrm{O}(\mathrm{v})\right)$ at different temperatures. 

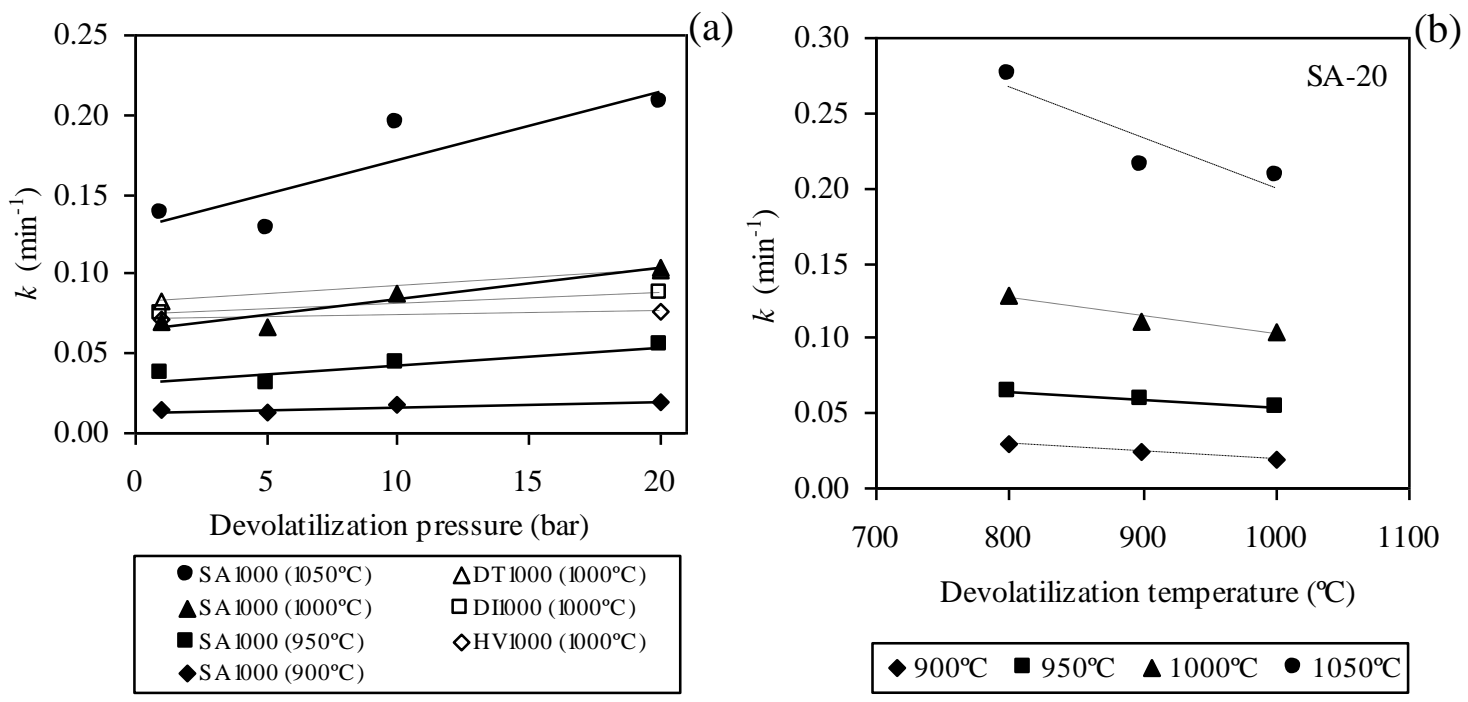

Fig. 4. Effect of the devolatilization pressure (a) and temperature (b) on the gasification apparent reaction rate of char, $k$, for different gasification temperatures $(900,950,1000$ and $\left.1050{ }^{\circ} \mathrm{C}\right)$. 


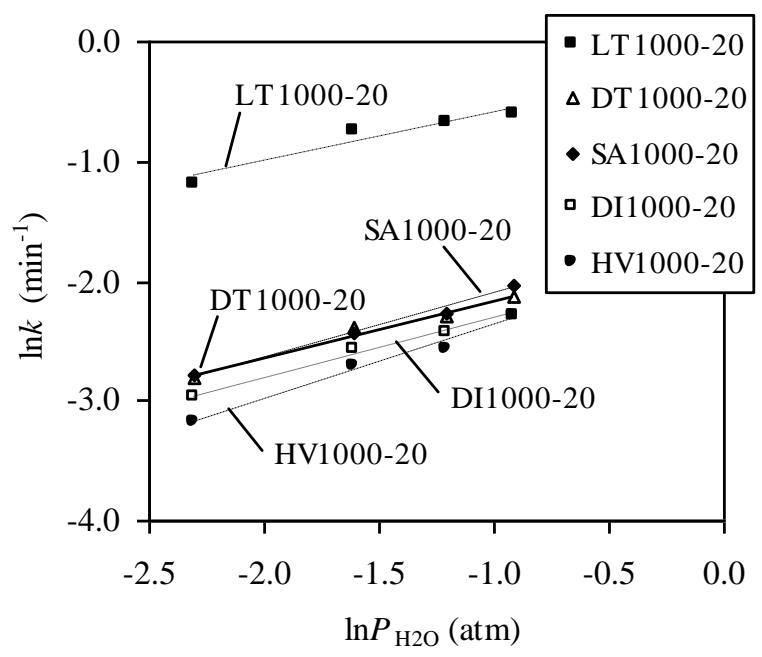

Fig. 5. Reactivity of coal chars obtained at $1000{ }^{\circ} \mathrm{C}$ and 20 atm as a function of the steam partial pressure. 